Original Research Article

\title{
Effect of Vitamin E on oxidative stress and outcome of treatment in patients of anxiety disorder
}

\author{
Sangita Devrao Jogdand ${ }^{1}$, Raju Kamlakarrao Shinde ${ }^{2 *}$
}

${ }^{1}$ Department of Pharmacology,

${ }^{2}$ Department of Surgery, Jawaharlal Nehru Medical College, Wardha, Maharashtra, India

Received: 08 March 2018 Accepted: 13 March 2018

\section{*Correspondence to:}

Dr. Raju Kamlakarrao Shinde,

Email: drsangitaraj@gmail.com

Copyright: (C) the author(s), publisher and licensee Medip Academy. This is an openaccess article distributed under the terms of the Creative Commons Attribution NonCommercial License, which permits unrestricted noncommercial use, distribution, and reproduction in any medium, provided the original work is properly cited.

\begin{abstract}
Background: The purpose of present study was to assess effect of Vitamin E administration on oxidative stress and outcome of treatment of anxiety disorder. Methods: 80 newly diagnosed patients of anxiety disorder of age 20 to 60 years were included in the study. They were divided in to two groups containing 40 patients in each group. Group-I patients were given treatment with Tablet Clonazepam $0.5 \mathrm{mg}$ orally daily at night for six months. Group-II patients were treated with Tablet Clonazepam 0.5mgand Capsule Vitamin E $400 \mathrm{mg}$ twice a day for 6 months. Levels of Mean MDA, SOD and anxiety score were assessed monthly for six months.
\end{abstract}

Results: Group-I $(\mathrm{N}=38)$ patients treated with Tablet Clonazepam $0.5 \mathrm{mg}$ orally at night show significant increase in Oxidative stress. Mean MDA- 18.80 \pm 0.37 increased to $27.97 \pm 0.81$, SOD- $0.143 \pm 0.004$ decreased to $0.111 \pm 0.004$ and decrease in mean anxiety score from first month $12.44 \pm 1.24$ to last month of treatment $2.55 \pm 0.72$. In group-II patients $(\mathrm{N}=37)$ treated with Clonazepam and Vitamin $\mathrm{E}$ there was decrease in mean MDA levels from $18.78 \pm 0.45$ to $12.56 \pm 0.54$ and increase in mean SOD levels from $0.141 \pm 0.007$ to $0.180 \pm 0.000$. There was reduced anxiety score in group-I from $12.44 \pm 1.24$ to $2.55 \pm 0.72$ and in group II from $12.54 \pm 1.26$ to $1.86 \pm 0.58$ which was statistically significant. p value $<0.05$.

Conclusions: Treatment of patients treated with Clonazepam showed a significant increase in oxidative stress. In patients treated with Clonazepam and Vitamin E there was more reduction in overall oxidative stress and anxiety.

Keywords: Anxiety disorder, Anxiety score, Oxidative stress

\section{INTRODUCTION}

Anxiety is a state of uneasiness or apprehension which may be because of subjective mental states initiated by various external and internal stressors. It is a normal response by an individual to danger or threat but it becomes abnormal when it is inappropriate to its time and severity. ${ }^{1}$ As per Diagnostic and Statistical Manual of Mental Disorder, $4^{\text {th }}$ ed. (Text Revision) (DSM-IV-TR) various anxiety disorders includes generalized anxiety disorder (GAD), Phobic disorder like social phobia, panic disorder (PD)and post traumatic disorder. ${ }^{2}$ Prevalence of anxiety disorder In India is $20.7 \%$ (18.7 to 22.7 ).It is found more in urban areas than rural areas which may be because of underreporting in rural areas. ${ }^{3}$ Environmental, genetic and developmental factors are implicated in the pathogenesis of anxiety disorder. It is found that there is association of anxiety disorders with oxidative stress. ${ }^{4}$ Oxidative stress is defined as "state in which oxidation exceeds antioxidant systems in the body secondary to a loss of the balance between them". 5 Free radicals are produced as by-product by the mitochondria during formation of ATP by using oxygen. These free radicals are formed as reactive oxygen species (ROS)and reactive nitrogen species (RNS). These reactive species have beneficial effects at low or moderate level but at high level they produce oxidative stress. Our body has a defence 
mechanism in the form of antioxidants to prevent the body from deleterious effects of these reactive species. Endogenous antioxidants are of two types, enzymatic and nonenzymatic. Enzymatic antioxidants include Superoxide dismutase (SOD), Catalase (CAT), Glutathione reductase (GRx) while non-enzymatic antioxidants include metabolic antioxidants like glutathione, bilirubin, lipoid acid and nutrients antioxidants like Vitamin E, Vitamin C, and Carotenoids. ${ }^{6}$ Treatment of anxiety disorder includes Benzodiazepines, selective serotonin reuptake inhibitors (SSRI), serotonin and norepinephrine reuptake inhibitors (SNRI) and other drugs. SSRI when used for the treatment of anxiety disorder needs to be given at a higher dose than required for the treatment of depression which may leads to side effects associated with the use of these drugs such as agitation, sexual side effects and suicidal tendency. ${ }^{7}$ Benzodiazepine are useful in the treatment of anxiety disorder as they have rapid onset of action but their long term use is associated with drug dependence, withdrawal syndrome on discontinuation and impaired cognition. ${ }^{8}$

Anxiety disorder are characterized by functional impairment due to worry, fatigue, muscle tension and insomnia which may affect social and occupational responsibility. ${ }^{9}$ Level of anxiety can be measured by using different scales such as The State-Trait Anxiety Inventory (STAI), Beck Anxiety Inventory (BAI), Hospital Anxiety and Depression Scale-Anxiety (HADS-A). These scales help to measure general symptoms of anxiety and its relationship with severity of anxiety disorder. Beck anxiety inventory contain total 21 items. Patient responds to the questionnaire on a 4-point Likert scale. The scale has a score from 0-63 in which score of 0-9 indicates normal or no anxiety, score of 10-18 suggests mild to moderate anxiety and the anxiety score from 19-29 indicates moderate to severe anxiety. Score from 30-63 suggests severe anxiety. ${ }^{10}$ Studies has shown that there is decreased levels of Vitamin E, C and Vitamin A in patients of anxiety disorder as compared to normal subjects. ${ }^{9,11,12}$

Hence this study was undertaken to compare the effect of antianxiety drug Clonazepam and supplementing vitamin $\mathrm{E}$ as an antioxidant on oxidative stress and outcome in patients of anxiety disorder.

\section{METHODS}

In this study we included 80 patients ofanxiety disorder diagnosed as per the Diagnostic and Statistical Manual of Mental Disorder, $4^{\text {th }}$ ed. (Text Revision) (DSM-IV-TR) of either sex between the age group of 20 to 60 years. Patients with comorbid depression and chronic illness such as hypertension, diabetes, drug dependence and taking antioxidants were excluded from the study. Enrolled patients were divided into two groups, containing 40 patients in each group. Anxiety Score was assessed by using Beck's Anxiety Inventory (BAI) prior to initiation of the treatment. Baseline oxidative stress was assessed by estimating the serum levels of Malondialdehyde (MDA) by Thiobarbituric acid (TBA) method and superoxide dismutase (SOD) by inhibition of auto-oxidation of Pyrogallol. ${ }^{13}$

Group I patients were given Tablet Clonazepam $0.5 \mathrm{mg}$ orally daily at night for a period of six months. Group II was prescribed Tablet Clonazepam $0.5 \mathrm{mg}$ orally daily at night and Capsule Vitamin E 400mg twice a day for six months. Serum MDA, SOD and anxiety score were assessed at the end of each month till six months. At the end of study anxiety score was correlated to assess the outcome of treatment on anxiety disorder. Comparison was done with student' ' $t$ ' test.

\section{RESULTS}

\section{Age and sex distribution}

Mean age of patients in group I was $32.21 \pm 10.36$ years, in group II was $36.56 \pm 10.41$ years respectively. There was no statistically significant difference in the patients age group distributed in two groups. Group I and II had17male and 21 female whereas in group II there were 22 males and 15 females.

Pre-treatment mean MDA levels in group I and group II were $18.80 \pm 0.37 \mathrm{nmol} / \mathrm{ml}$ and $18.78 \pm 0.45 \mathrm{nmol} / \mathrm{ml}$ respectively which was statistically non-significant. From $1^{\text {st }}$ month onwards there was progressive increase in mean MDA levels in group-I from baseline to $27.97 \pm 0.81 \mathrm{nmol} / \mathrm{ml}$ whereas there was progressive decrease in mean MDA levels in group-II from baseline to $12.56 \pm 0.54 \mathrm{nmol} / \mathrm{ml}$ which was statistically significant as $\mathrm{p}=0.0001$.

Mean SOD levels at baseline in group-I and group-II were $0.143 \pm 0.004 \mathrm{U} / \mathrm{gm}$. of $\mathrm{Hb}$ and $0.141 \pm 0.007 \mathrm{U} / \mathrm{gm}$. of $\mathrm{Hb}$. respectively which was statistically not significant between the groups. From first month onwards, there was progressive decrease in mean SOD levels in group-I from baseline to $0.111 \pm 0.004 \mathrm{U} / \mathrm{gm}$. of $\mathrm{Hb}$, whereas there was progressive increase in mean SOD levels in group II from baseline to $0.180 \pm 0.000 \mathrm{U} / \mathrm{gm}$. of $\mathrm{Hb}$ respectively which was statistically significant (Table 1).

Mean anxiety score at baseline in group-I and group-II was $12.44 \pm 1.24$ and $12.43 \pm 2.20$ respectively which was nonsignificant between the groups. There was progressive reduction in anxiety score in group-I and group-II from first month to last month of treatment. There was significant difference in anxiety score in group-I and group-II at $2^{\text {nd }}$, 3rd and $4^{\text {th }}$ month of treatment which became non-significant at $5^{\text {th }}$ month and significant at $6^{\text {th }}$ month of treatment.

\section{DISCUSSION}

In this study entitled "Role of Vitamin E in oxidative stress and outcome of anxiety disorder" we included 80 patients of anxiety disorder divided in two groups containing 40 
patients in each group of either sex between the age groups of 20 to 60 years.

Table 1: Comparison of mean MDA, SOD and Anxiety Scores two groups by Student's unpaired t test.

\begin{tabular}{|c|c|c|c|c|c|c|c|c|c|}
\hline & & \multicolumn{3}{|c|}{ Mean MDA } & \multicolumn{2}{|c|}{ Mean SOD } & \multicolumn{2}{|c|}{ Mean AS } & \multirow[b]{2}{*}{ p-value } \\
\hline & Group & $\mathbf{N}$ & Mean & $\begin{array}{l}\text { Std. } \\
\text { deviation }\end{array}$ & Mean & $\begin{array}{l}\text { Std. } \\
\text { deviation }\end{array}$ & Mean & $\begin{array}{l}\text { Std. } \\
\text { deviation }\end{array}$ & \\
\hline \multirow{2}{*}{ Pre Test } & Group 1 & 38 & 18.80 & 0.37 & 0.143 & 0.0048 & 12.44 & 1.24 & \multirow{2}{*}{$\begin{array}{l}0.83, \mathrm{NS}^{\wedge} \\
0.15, \mathrm{NS} \# \\
0.97, \mathrm{NS}^{*}\end{array}$} \\
\hline & Group 2 & 37 & 18.78 & 0.45 & 0.141 & 0.0072 & 12.43 & 2.20 & \\
\hline \multirow{2}{*}{1 month } & Group 1 & 38 & 18.51 & 0.72 & 0.140 & 0.0049 & 11.21 & 1.06 & \multirow{2}{*}{$0.0001, \mathrm{~S}$} \\
\hline & Group 2 & 37 & 17.04 & 0.55 & 0.145 & 0.0064 & 10.08 & 1.40 & \\
\hline \multirow{2}{*}{2 months } & Group 1 & 38 & 19.52 & 0.82 & 0.139 & 0.0053 & 9.78 & 1.06 & \multirow{2}{*}{$0.0001, \mathrm{~S}$} \\
\hline & Group 2 & 37 & 15.88 & 0.55 & 0.153 & 0.0047 & 8.05 & 1.20 & \\
\hline \multirow{2}{*}{3 months } & Group 1 & 38 & 22.72 & 0.83 & 0.135 & 0.0068 & 7.60 & 1.17 & \multirow{2}{*}{$0.0001, \mathrm{~S}$} \\
\hline & Group 2 & 37 & 14.91 & 0.53 & 0.161 & 0.0048 & 6.72 & 0.96 & \\
\hline \multirow{2}{*}{4 months } & Group 1 & 38 & 24.27 & 0.83 & 0.125 & 0.0055 & 5.68 & 1.45 & \multirow{2}{*}{$\begin{array}{l}0.0001, \mathrm{~S} \\
0.68 \mathrm{NS}^{\$}\end{array}$} \\
\hline & Group 2 & 37 & 14.07 & 0.54 & 0.165 & 0.0050 & 5.56 & 1.01 & \\
\hline \multirow{2}{*}{5 months } & Group 1 & 38 & 25.86 & 0.84 & 0.116 & 0.0053 & 4.07 & 1.04 & \multirow{2}{*}{$\begin{array}{l}0.0001, \mathrm{~S} \\
0.24 \mathrm{NS}^{\$}\end{array}$} \\
\hline & Group 2 & 37 & 13.22 & 0.53 & 0.174 & 0.0050 & 3.81 & 0.93 & \\
\hline \multirow{2}{*}{6 months } & Group 1 & 38 & 27.97 & 0.81 & 0.111 & 0.0043 & 2.55 & 0.72 & \multirow{2}{*}{$0.0001, \mathrm{~S}$} \\
\hline & Group 2 & 37 & 12.56 & 0.54 & 0.180 & 0.0000 & 1.86 & 0.58 & \\
\hline
\end{tabular}

$\wedge$-p value for MDA, \# p value of SOD, * p value of anxiety score

$\$$ Non-significant difference in mean anxiety score

There were five drop outs, two patients from group-I and three patients from group-II after two months. Mean age of patients in group-I was $32.21 \pm 10.36$ and group-II was 36.07 years.

Increased oxidative stress noted in Group-I supported by increased levels of MDA and decreased levels of SOD progressively from baseline to last assessment at six months, chronic administration of diazepam increases levels of MDA by increasing lipid peroxidation with decrease in levels of SOD and Glutathione in rat liver as compared to normal. please modify reference as 1 instead of. ${ }^{14}$ In this study we also found that clonazepam also produces increased oxidative stress as evident by stress markers.

Clonazepam produce its anxiolytic action by acing on $\alpha_{2}$ subunit of GABA-A receptor and enhances inhibitory action of GABA by opening of chloride channel causing hyperpolarization of neurones which becomes resistant to excitation. $^{8}$ Due to this action there was significant reduction in anxiety score in patients treated with Clonazepam though there was significant increase in oxidative stress.

In this study, group-II patients who were treated with Clonazepam and Vitamin E there was significant decrease in oxidative stress from baseline till last assessment. There was significant decrease in anxiety score from first month to last month of treatment except at fourth and fifth months. Vitamin E is a chain breaking antioxidant act by interacting with cell membrane because of its lipid solubility and interruption of free radical chain reaction. Vitamin is a peroxyl radical scavenger and protect polyunsaturated fatty acids within the membrane phospholipid, one molecule of Vitamin E gives protection against 2000 phospholipid molecules, similar findings of reduction in oxidative stress was observed by Mansour et al, in their study in patients of cardiovascular disease in which supplementation of vitamin $\mathrm{E}$ for two months leads to significant increase in vitamin $\mathrm{E}$ levels as compared to normal subjects as well as there was significant decrease in levels of MDA and increase in levels of SOD as compared to its baseline which may be because of antioxidant action of Vitamin E. ${ }^{14,15}$ In a study conducted by Medhavi Gautam significant decrease in anxiety score was observed in experimental group who received antianxiety drug combined with antioxidants for six week where pre-treatment score of 36.57 was decreased to 3.57 whereas in control group who received only antianxiety medication pre-treatment score of 37.29 was decreased to 13.76. ${ }^{12}$ These finding of reduced oxidative stress suggest effective role of vitamin $\mathrm{E}$ in maintaining the homeostasis along with early reduction in the patients' anxiety related behaviour.

\section{CONCLUSION}

Use of vitamin $\mathrm{E}$ was effective in reducing the anxiety score effectively compared to only treatment with clonazepam and maintaining the internal homeostasis in anxiety disorder patients. 
Funding: No funding sources

Conflict of interest: None declared

Ethical approval: The study was approved by the Institutional Ethics Committee

\section{REFERENCES}

1. Krolow R, Arcego DM, Noschang C, Weis SN, Dalmaz C. Oxidative imbalance and anxiety disorders. Current neuropharmacology. 2014 Mar;12(2):193204.

2. Shelton CI. Diagnosis and Management of Anxiety Disorders. J Am Osteopath Assoc. 2004;104(3,1):S25.

3. Trivedi JK, Gupta PK. An overview of Indian research in anxiety disorders. Indian J Psychiatry. 2010 Jan;52(1):S210-8.

4. Salim S. Oxidative Stress and Psychological Disorders. Curr Neuropharmacol. 2014 Mar;12(2):140-7.

5. Yoshikawa T, Naito Y. What is oxidative stress? Japan Medical Association Journal. 2002;45(7):271-6.

6. Pham-Huy LA, He H, Pham-Huy C. Free Radicals, Antioxidants in Disease and Health. Int J Biomed Sci IJBS. 2008 Jun;4(2):89-96.

7. Farach FJ, Pruitt LD, Jun JJ, Jerud AB, Zoellner LA, Roy-Byrne PP. Pharmacological treatment of anxiety disorders: Current treatments and future directions. J Anxiety Disord. 2012 Dec;26(8):833-43.

8. Benzodiazepines: Uses, Side Effects, Interactions \& Warnings Mar 3]. Available at: https://www.drugs.com/article/benzodiazepines.html

9. Reena N, Deepti P, Shruti K. Markers of oxidative stress in generalized anxiety psychiatric disorder: therapeutic implications. Journal of Stress Physiology \& Biochemistry. 2012;8(2).

10. Julian LJ. Measures of Anxiety. Arthritis Care Res. 2011. Available at https://www.ncbi.nlm.nih.gov/pmc/articles/PMC3879 951/

11. Bal N, Acar ST, Yazici A, Yazici K, Tamer L. Altered levels of malondialdehyde and vitamin $\mathrm{E}$ in major depressive disorder and generalized anxiety disorder. Dusunen Adam. 2012 Sep 1;25(3):206.

12. Gautam M, Agrawal M, Gautam M, Sharma P, Gautam AS, Gautam S. Role of antioxidants in generalised anxiety disorder and depression. Indian J Psychiatry. 2012;54(3):244-47.

13. Marklund S, Marklund G. Involvement of the superoxide anion radical in the autoxidation of pyrogallol and a convenient assay for superoxide dismutase. Eur J Biochem. 1974 Sep 16;47(3):469-74.

14. Rizvi S, Raza ST, Ahmed F, Ahmad A, Abbas S, Mahdi F. The Role of Vitamin E in Human Health and Some Diseases. Sultan Qaboos Univ Med J. 2014 May;14(2):e157-65.

15. Karajibani M, Hashemi M, Montazerifar F, Dikshit M. Effect of vitamin $\mathrm{E}$ and $\mathrm{C}$ supplements on antioxidant defense system in cardiovascular disease patients in Zahedan, southeast Iran. J Nutr Sci Vitaminol (Tokyo). 2010;56(6):436-40.

Cite this article as: Jogdand SD, Shinde RK. Effect of Vitamin E on oxidative stress and outcome of treatment in patients of anxiety disorder. Int J Basic Clin Pharmacol 2018;7:590-3. 